\title{
Eligibility for PCSK9 treatment in 734 Hypercholesterolemic patients referred to a regional cholesterol treatment center with $\mathrm{LDL}$ cholesterol $\geq 70 \mathrm{mg} / \mathrm{dl}$ despite maximal tolerated cholesterol lowering therapy
}

Charles J. Glueck*, Parth Shah, Naila Goldenberg, Marloe Prince, Kevin Lee, Vybhav Jetty, Ashwin Kumar, Michael Goldenberg and Ping Wang

\begin{abstract}
Background: LDL cholesterol (LDLC) lowering has been revolutionized by PCSK9 inhibitors, Alirocumab (Praluent) and Evolocumab (Repatha), approved as adjuncts to maximally tolerated cholesterol lowering therapy in heterozygous (HeFH) or homozygous (HoFH) familial hypercholesterolemia, and/or clinical atherosclerotic cardiovascular disease (CVD) where LDLC lowering is insufficient.

Methods: We applied FDA and insurance eligibility criteria for PCSK9 inhibitor use in 734 hypercholesterolemic patients serially referred over 3 years who then received $\geq 2$ months maximally tolerated LDLC lowering therapy with follow up LDLC $\geq 70 \mathrm{mg} / \mathrm{dl}$, and in 50 patients approved by insurance for PCSK9 inhibitors. We documented the percentage of patients with HeFH and/or CVD who met FDA and insurance criteria for PCSK9 inhibitor therapy using LDLC goal-based guidelines.

Results: Of 734 patients with LDLC $\geq 70 \mathrm{mg} / \mathrm{dl}$ after $\geq 2$ months maximally tolerated LDLC lowering therapy, 220 (30\%) had HeFH and/or CVD with LDLC > 100 mg/dl, meeting FDA-insurance criteria for PCSK9 inhibitor therapy. Another 66 (9\%) patients were statin intolerant, without HeFH or CVD. Of the 50 patients whose PCSK9 inhibitor therapy was approved for insurance coverage, 45 (90 \%) had LDLC > $100 \mathrm{mg} / \mathrm{dl}$ after $\geq 2$ months on maximally tolerated LDLC lowering therapy. Seventeen of these 50 patients (34 \%) had HeFH without CVD (LDLC on treatment $180 \pm 50 \mathrm{mg} / \mathrm{dl}$ ), 15 (30\%) had CVD without HeFH (LDLC on treatment $124 \pm 26 \mathrm{mg} / \mathrm{dl}$ ), 14 (28 \%) had both HeFH and CVD (LDLC on treatment $190 \pm 53 \mathrm{mg} / \mathrm{dl})$, and 4 (8 \%) had neither HeFH nor CVD (LCLC $142 \pm 11 \mathrm{mg} / \mathrm{dl})$.

(Continued on next page)
\end{abstract}

\footnotetext{
* Correspondence: cjglueck@mercy.com

From the Cholesterol, Metabolism, and Thrombosis Center, Jewish Hospital

of Cincinnati, Cincinnati, USA
} 
(Continued from previous page)

Conclusion: Of 734 patients referred for LDLC reduction, with $L D L C \geq 70 \mathrm{mg} / \mathrm{dl}$ after $\geq 2$ months on maximally tolerated therapy, 220 (30 \%) had HeFH and/or CVD with LDLC > 100 mg/dl, meeting FDA-insurance criteria for PCSK9 inhibitor therapy as an adjunct to diet-maximally tolerated cholesterol lowering therapy in HeFH or CVD. If $30 \%$ of patients with high LDLC and HeFH-CVD are eligible for PCSK9 inhibitors, then specialty pharmaceutical pricing models ( $\sim 14,300 /$ year) will collide with tens of millions of HeFH-CVD patients. We speculate that if there was a $50 \%$ reduction in CVD, then there would be savings of $\$ 245$ billion, in the middle of the range of estimated PCSK9 inhibitor costs of \$185-342 billion. Whether the health care savings arising from the anticipated reduction of CVD events by PCSK9 inhibitors justify their extraordinary costs in broad population use remains to be determined.

Keywords: PCSK9 inhibitors, LDL cholesterol (LDLC), Heterozygous familial hypercholesterolemia (HeFH), Atherosclerotic cardiovascular disease (CVD)

\section{Background}

Lowering of LDL cholesterol (LDLC) has been revolutionized by the recent release of the PCSK9 inhibitors, Alirocumab (Praluent) and Evolocumab (Repatha). PCSK9 inhibitors are approved for patients with heterozygous familial hypercholesterolemia $(\mathrm{HeFH})$, homozygous familial hypercholesterolemia (HoFH), and for patients with atherosclerotic cardiovascular disease (CVD) unable to achieve LDLC goals despite maximal tolerated cholesterol-lowering therapy, including zero dose tolerance (statin intolerance) [1-3]. Preliminary results of safety-efficacy controlled clinical trials, although not powered or designed to definitively assess CVD events, showed about a $50 \%$ risk reduction in CVD events $[1,2]$.

If the annual cost of the PCSK9 inhibitors were to remain at $\$ 14,000-14,600$, then specialty pharmaceutical pricing models previously reserved for drugs which benefitted limited patient populations will collide with prospective treatment cohorts in the tens of millions of patients at high risk for CVD, when using PCSK9 inhibitors as an adjunct to diet-maximally tolerated cholesterol lowering therapy in heterozygous $(\mathrm{HeFH})$ or homozygous $(\mathrm{HoFH})$ familial hypercholesterolemia, or clinical atherosclerotic cardiovascular disease (CVD). We have applied FDA approved and commercial insurance eligibility criteria for PCSK9 inhibitor use in 734 patients serially referred to our Cholesterol Diagnosis and Treatment center and receiving $\geq 2$ months maximally tolerated LDLC lowering diet-drug therapy with follow up LDLC $\geq 70 \mathrm{mg} / \mathrm{dl}$, to obtain estimates of the percentage of patients with $\mathrm{HeFH}$ and CVD who meet FDA and commercial insurance eligibility for PCSK9 inhibitor treatment using LDLC goal-based guidelines $[4,5]$.

\section{Methods}

The study followed a protocol approved by the Jewish Hospital Institutional Review Board (JH \#12-03).

We assessed 734 hypercholesterolemic patients consecutively referred to our Cholesterol Treatment Center from May 2012 to September 2015, who subsequently received $\geq 2$ months of maximally tolerated diet-drug LDLC lowering therapy, with last follow up LDLC $\geq$ $70 \mathrm{mg} / \mathrm{dl}$. All patients were instructed to consume a cholesterol lowering diet by a registered dietitian, and received maximally tolerated LDLC lowering therapy, predominantly with statins and a small percentage were also taking ezetimibe and/or colesevelam.

We assessed 50 patients who were approved for PCSK9 inhibitor therapy with Evolocumab or Alirocumab coverage by their medical insurance programs by applying the Simon Broome criteria for $\mathrm{HeFH}$ [6] and/or CVD with LDLC above target (>100 mg/dl [4]) despite maximally tolerated LDLC lowering therapy.

After an overnight fast, lipids and lipoprotein cholesterols were serially measured by LabCorp with direct measurement of LDLC if triglycerides were $>400 \mathrm{mg} / \mathrm{dl}$. Heterozygous familial hypercholesterolemia $(\mathrm{HeFH})$ was defined by LDLC $\geq 190 \mathrm{mg} / \mathrm{dl}$ and the presence of tendon xanthomas and/or by hypercholesterolemic first degree relatives (Simon Broome criteria [6]). Atherosclerotic cardiovascular disease (CVD) included medical recordphysician referral documented coronary artery, carotid, aortic, or peripheral vascular atherosclerosis, as well as transient ischemic attack and ischemic stroke. Patients intolerant to $\geq$ 3 statin medications were identified as "statin intolerant."

Separately, we assessed fasting lipid profiles in 8053 patients at their first visit, consecutively referred to our center over the last 30 years for diagnosis and treatment of hypercholesterolemia. The 734 patients in the current report studied after $\geq 2$ months on maximal lipid lowering therapy were a subset of these 8053 patients.

\section{Results}

Of the 734 patients, 210 (29\%) had HeFH, 180 (25\%) CVD, and 179 were statin intolerant (24\%), Fig. 1. In the 180 patients who had CVD, the first CVD event was at age $55 \pm 13$, median 55 years. Of the 734 patients, 66 (9\%) were statin intolerant, without $\mathrm{HeFH}$ or CVD, Fig. 1. After $\geq 2$ months on maximum tolerated LDLC 


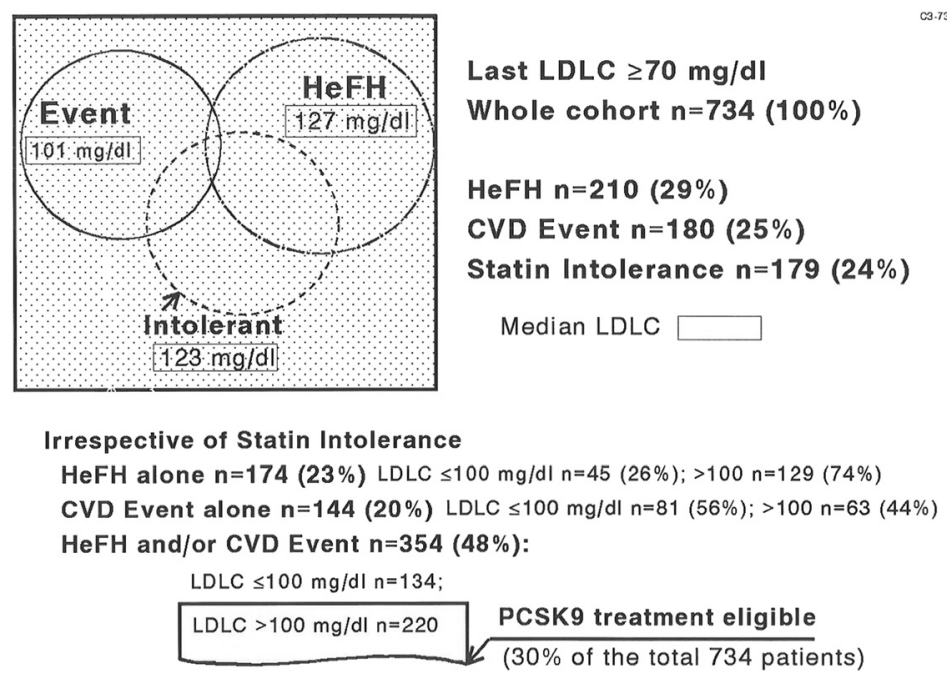

$3.734 \mathrm{P} 15.10$

Statin Intolerance only, not HeFH, not CVD Event, $n=66(9 \%)$

Fig. 1 Heterozygous familial hypercholesterolemia (HeFH) and atherosclerotic cardiovascular events (CVD) in 734 patients with LDLC $\geq 70$ mg/dl after $\geq 2$ months maximally tolerated cholesterol-lowering therapy. Two hundred and twenty patients with HeFH and/or CVD (30 \% of the referred cohort) eligible for PCSK9 inhibitor therapy by FDA and commercial insurance guidelines by virtue of LDLC on maximal therapy $>100$

lowering therapy, median LDLC in patients with $\mathrm{HeFH}$ was $127 \mathrm{mg} / \mathrm{dl}$, in those with CVD events, $101 \mathrm{mg} / \mathrm{dl}$, and in statin intolerant patients, $123 \mathrm{mg} / \mathrm{dl}$, Fig. 1.

Two hundred and twenty of the 734 patients (30\%) were eligible by both FDA and commercial insurance criteria for PCSK9 inhibitor treatment, by virtue of having $\mathrm{HeFH}$ and/or CVD, and also having LDLC > $100 \mathrm{mg} / \mathrm{dl}$ on maximally tolerated lipid lowering therapy, Fig. 1. Of these 220 patients, 161 had taken statins, 6 statins plus colesevelam, 3 colesevelam only, 11 statins plus ezetimibe, and 4 statins plus colesevelam and ezetimibe. Of these 220 patients, 56 (25\%) were unable to take any statins, being intolerant to $\geq 3$ different statins.

Of the 220 patients having $\mathrm{HeFH}$ and/or a CVD event with LDLC $>100 \mathrm{mg} / \mathrm{dl}$ on maximal tolerated cholesterol lowering treatment (Fig. 1), 129 had HeFH alone, with LDLC on therapy $160 \pm 51$, median $147 \mathrm{mg} / \mathrm{dl}$, 63 had CVD events alone, with LDLC on therapy $134 \pm 29$, median $121 \mathrm{mg} / \mathrm{dl}$, and 28 had both $\mathrm{HeFH}$ and CVD, with LDLC on therapy $178 \pm 46$, median $174 \mathrm{mg} / \mathrm{dl}$. In those 91 patients with CVD, the first CVD event occurred at age $54 \pm 13$, median 56 years.

Fifty patients were approved for PCSK9 inhibitor therapy (Evolocumab or Alirocumab) coverage by their medical insurance programs. Forty-five of these 50 patients $(90 \%)$ had LDLC $>100 \mathrm{mg} / \mathrm{dl}$ after $\geq 2$ months on maximally tolerated LDLC lowering therapy, while in the other 5 patients, LDLC was $80-100 \mathrm{mg} / \mathrm{dl}$. Seventeen of the 50 patients (34\%) had only $\mathrm{HeFH}$ but no CVD, with LDLC on treatment $180 \pm 50 \mathrm{mg} / \mathrm{dl}$, median $182 \mathrm{mg} / \mathrm{dl}$. Fifteen of the 50 patients (30\%) had only
CVD but no $\mathrm{HeFH}$, with LDLC on treatment $124 \pm$ $26 \mathrm{mg} / \mathrm{dl}$, median $131 \mathrm{mg} / \mathrm{dl}, 14$ of the 50 (28\%) had both $\mathrm{HeFH}$ and CVD, with on-treatment LDLC $190 \pm$ $53 \mathrm{mg} / \mathrm{dl}$, median $191 \mathrm{mg} / \mathrm{dl}$, and the other 4 (8\%) patients had no HeFH nor CVD, with LDLC 129, 141, 141, $156 \mathrm{mg} / \mathrm{dl}$. The patients with CVD had their first CVD event at age $56 \pm 11$, median 58 years.

Upon evaluation of initial visit LDLC levels in 8053 patients referred to our center over the last 30 years, $9 \%$ had LDLC $\geq 190 \mathrm{mg} / \mathrm{dl}, 12 \%$ fell between 160 and $190 \mathrm{mg} / \mathrm{dl}, 20 \%$ between 130 and $160 \mathrm{mg} / \mathrm{dl}, 28 \%$ between 100 and $130 \mathrm{mg} / \mathrm{dl}$, and $31 \%$ had LDLC $<100 \mathrm{mg} / \mathrm{dl}$, Tables 1 and 2. Overall, $41 \%$ of our 8053 referred patients had LDLC $\geq 130 \mathrm{mg} / \mathrm{dl}$ at their first referral visit, Tables 1 and 2. If LDLC $\geq 160 \mathrm{mg} / \mathrm{dl}$ is used as a cutoff for identification of hypercholesterolemic patients deserving treatment, $21 \%$ of our 8053 patients had LDLC $\geq 160$, and if LDLC of 190 is used as a treatment cutoff, $9.1 \%$ were above this level, Tables 1 and 2 .

\section{Discussion}

Large numbers of subjects with elevated LDLC fail to achieve treatment targets [7-9], for multiple reasons including statin intolerance $[10,11]$, expense, lack of insurance coverage, or variations in statin availability across states in insurance, race, and ethnicity [7]. Beyond statin effects, the PCSK9 inhibitors now offer the promise of optimizing LDLC in a majority of patients with $\mathrm{HeFH}, \mathrm{CVD}$, and statin intolerance [2, 5, 12-15]. The issue of healthcare systems either facilitating or hindering optimal delivery of hyperlipidemia management 
Table 1 The distribution of low density lipoprotein cholesterol (LDLC) in 8053 patients serially referred to the Cincinnati Cholesterol Center for diagnosis and therapy of hypercholesterolemia

\begin{tabular}{lllllll}
\hline $\begin{array}{l}\text { Categorized by } \\
\text { triglyceride levels }\end{array}$ & $\begin{array}{l}\mathrm{LDLC}<100 \\
\mathrm{mg} / \mathrm{dl}\end{array}$ & $100 \leq \mathrm{LDLC}<130$ & $130 \leq \mathrm{LDLC}<160$ & $160 \leq \mathrm{LDLC}<190$ & $\begin{array}{l}\text { LDLC } 190 \\
\text { mg/dl }\end{array}$ & $\begin{array}{l}\text { Whole row } \\
\text { Percent of row }\end{array}$ \\
\hline TG $<200 \mathrm{mg} / \mathrm{dl}$ & $1719(68 \%)$ & $1567(71 \%)$ & $1108(68 \%)$ & $617(64 \%)$ & $446(61 \%)$ & $5457(68 \%)$ \\
$200 \leq \mathrm{TG}<250$ & $198(8 \%)$ & $230(10 \%)$ & $190(12 \%)$ & $126(13 \%)$ & $111(15 \%)$ & $855(11 \%)$ \\
$250 \leq \mathrm{TG}<300$ & $150(6 \%)$ & $132(6 \%)$ & $115(7 \%)$ & $85(9 \%)$ & $83(11 \%)$ & $565(7 \%)$ \\
$\mathrm{TG} \geq 300 \mathrm{mg} / \mathrm{dl}$ & $445(18 \%)$ & $292(13 \%)$ & $215(13 \%)$ & $134(14 \%)$ & $90(12 \%)$ & $1176(15 \%)$ \\
Whole Column & 2512 & 2221 & 1628 & $(12 \%)$ & $(962 \%)$ & $8053(100 \%)$ \\
Percent of column & $(31 \%)$ & $(28 \%)$ & & & $(100 \%)$ \\
\hline
\end{tabular}

will now be amplified by the paradigm-shifting improvement in LDLC lowering by the PCSK9 class of medications $[1,2,16]$ at an annual price of $\$ 14,000-14,600$ per patient.

In the current study, of the 734 patients referred to a Lipid Center for diagnosis and treatment of high LDLC and/or CVD, with LDLC $\geq 70 \mathrm{mg} / \mathrm{dl}$ despite maximally tolerated cholesterol lowering therapy, $30 \%$ were eligible by FDA [17] and insurance carrier criteria for PCSK9 inhibitor therapy. Our analysis is focused on those high risk patients for whom PCSK9 inhibitors are specifically indicated $[1,2,17]$ and restricted by medical insurance carriers, as an adjunct to diet-maximally tolerated cholesterol lowering therapy in adults with $\mathrm{HeFH}$, and/ or CVD who require additional lowering of LDLC. As for the general population, the recent CDC report on cholesterol treatment in the general population of the US [3] found that $36.7 \%$ (78 million) adults (> 21 years) were eligible for cholesterol-lowering medication, but of this group, only $55 \%$ were actively taking a cholesterol lowering medication ( $90 \%$ a statin drug). If $30 \%$ of the 78 million hypercholesterolemic adults in the general US population [3] were, as in our current study, eligible by FDA [17] and insurance carrier criteria for PCSK9 therapy, this would include $11 \%$ of the adult population or 23.4 million adults.

The population cost of PCSK9 inhibitor therapy largely depends on the number of subjects judged to be at high risk by virtue of $\mathrm{HeFH}$ with high LDLC [18-20], and/or by CVD with LDLC above target goals [4] despite maximally tolerated therapy. In 1.3 million adults, Elshazly et al. [18] identified the $97^{\text {th }}$ percentile of LDLC as $190,160-190$ as the $90^{\text {th }}-97^{\text {th }}$ percentile, and $130-160 \mathrm{mg} / \mathrm{dl}$ the $72^{\text {nd }}-90^{\text {th }}$ percentile. In our 8053 patients referred for diagnosis and therapy of hypercholesterolemia, $9 \%$ had LDLC $\geq 190 \mathrm{mg} / \mathrm{dl}$ and
$21 \%$ had LDLC $\geq 160 \mathrm{mg} / \mathrm{dl}$. Hence, up to $21 \%$ of our hypercholesterolemic referrals had LDLC levels usually associated with $\mathrm{HeFH}$, making them good candidates for approval [17] of PCSK9 therapy by commercial insurance carriers. Toth et al. [20] examined NHANES 20052006 data, and identified $27 \%$ with high LDLC (risk stratum-specific). In studies from the US general population 2009-2010 NHANES survey, Fryar et al. [19] identified "uncontrolled high LDLC $(\geq 130 \mathrm{mg} / \mathrm{dl})$ " in $28 \%$ of adults. Kuklina et al. have estimated that more than one-quarter of adults aged 40-74 have high LDLC [21]. If $21-36.7 \%[3,19-21]$ of the general adult US population is judged to have high LDLC, as above, then a high LDLC cohort would range from 45 to 78 million subjects. Extrapolating from our referral cohort where $30 \%$ of hypercholesterolemic patients had $\mathrm{HeFH}$ and/ or CVD with LDLC $\geq 100 \mathrm{mg} / \mathrm{dl}$ despite maximally tolerated cholesterol lowering therapy, it is possible that 13 to 23 million patients might be candidates for treatment with PCSK9 inhibitors.

Direct costs of CVD include those related to the diagnosis and treatment of the condition, while indirect costs include lost work productivity, loss of future productivity, unemployment, or death [22]. In 2010, CVD related direct medical costs in the United States were estimated to be $\$ 273$ billion, and indirect costs 172 billion, $\$ 445$ billion total [23]. The American Heart Association estimated that direct and indirect costs of medical care for CVD approached $\$ 450$ billion in 2010, and are projected to rise to over $\$ 1$ trillion by 2030 [24]. Heidenrich et al. [23] have projected that by 2030, $40.5 \%$ of the US population may have some form of CVD. From 2010 to 2030, real total direct medical costs of CVD are projected to triple, from $\$ 273$ billion to $\$ 818$ billion. Real indirect costs (due to lost productivity) for all CVD are estimated to increase from $\$ 172$

Table 2 LDLC percentiles in the 8053 patients

\begin{tabular}{|c|c|c|c|c|c|c|c|c|c|c|}
\hline LDLC percentiles & Mean \pm SD & $2.5^{\text {th }}$ percentile & $5^{\text {th }}$ & $10^{\text {th }}$ & $25^{\text {th }}$ & 50th & $75^{\text {th }}$ & $90^{\text {th }}$ & $95^{\text {th }}$ & $97.5^{\text {th }}$ \\
\hline LDLC (mg/dl) & $126 \pm 48$ & 49 & 60 & 72 & 93 & 120 & 153 & 186 & 212 & 234 \\
\hline
\end{tabular}


billion in 2010 to $\$ 276$ billion in 2030, an increase of $61 \%$ [23]. Programs targeted to prevention of CVD should provide substantial overall cost savings $[25,26]$.

Given current pricing of $\$ 14,000-14,600$ per patient per year, annual PCSK9 inhibitor costs might approximate $\$ 185-\$ 342$ billion, reflecting the use of a currently expensive drug for an endemic disease, CVD, the leading cause of mortality in the USA [23, 27]. In 2011 the annual costs for CVD and stroke were estimated to be $\$ 320.1$ billion [24]. If, speculatively, CVD incidence could be halved by PCSK9 therapy [1, 2, 16], direct annual savings would be estimated to be $\$ 160$ billion, and indirect annual savings might be $\$ 85$ billion [23], altogether $\$ 245$ billion savings, in the middle of the range of estimated PCSK9 inhibitor costs of \$185-342 billion.

Whether and to what degree PCSK9 inhibitor use will facilitate overall reductions in the cost to society will depend on how widely they will be used, and the percentage reduction of all cause and CVD mortality [28]. Overall costs to society also need to include analysis of any potential adverse effects arising from PCSK9 inhibitor use. On Alirocumab, injection site reactions, myalgia, neurocognitive events, and ophthalmologic events were more common than on placebo [1]. On Evolocumab, nonspecific adverse events (arthralgia, headache, limb pain, fatigue, and neurocognitive events) were reported more frequently than in the placebo group [2]. In a meta-analysis of 25 randomized controlled trials with PCSK9s, Zhang et al. [16] "detected largely no significant difference in major adverse events rates between antibody administration and control treatment, and no difference between different dosages of Evolocumab." Within this frame of reference, we speculate that costs to society arising from adverse effects specifically attributed to PCSK9 inhibitors may be minimal.

Changes in lifestyle (diet and exercise), to the extent that they lower CVD event rates [29-31], may play a role in the cost-benefit analysis by further reducing CVD event rates in concert with PCSK9 therapy [28].

When statin medications were introduced, cost of illness calculations were made [32] with the conclusion that "When only direct medical care costs were considered, the incremental cost-effectiveness ratios for lifelong therapy with atorvastatin calcium, $10 \mathrm{mg} /$ day, were generally positive, ranging from a few thousand to nearly $\$ 20,000$ per year of life saved". When the societal point of view was adopted and indirect costs were included, the total costs were generally negative, representing substantial cost savings (up to $\$ 50,000$ per year of life saved) and increased life expectancy for most groups of individuals. Grover et al. [32] concluded that adding the indirect CVD costs associated with productivity losses at work and home can result in forecasted cost savings to society as a whole such that lipid therapy could potentially save lives and money. Cost effectiveness was also estimated from the use of Crestor $(20 \mathrm{mg} /$ day) in the JUPITER trial [33], and it was concluded that the treatment was cost-effective for higher risk patients, Framingham CVD risk $\geq 10 \%$. Song et al. [22] reported that prevention or reduction in CVD events could result in cost-savings for employers.

Strengths of our study include documentation that, of patients referred to a regional center for therapy of high LDLC, $30 \%$ had HeFH and/or CVD, and despite maximal LDLC lowering therapy, retained LDLC $>100 \mathrm{mg} /$ $\mathrm{dl}$, meeting both FDA indications [17] and commercial insurance coverage eligibility. We also evaluated a group of 50 patients approved for and already receiving insurance coverage for PCSK9 inhibitor therapy, who had $\mathrm{HeFH}$ and/or CVD, whose suboptimal LDLC lowering despite maximal lipid lowering therapy, emphasizes the medical necessity of PCSK9 inhibition in high risk patients. It is also noteworthy that within the 50 approved patients, there were five with LDLC in the $80-97 \mathrm{mg} / \mathrm{dl}$ range. Limitations include bias towards higher LDLC and CVD by virtue of referral to a regional Cholesterol Treatment Center, which would increase the percentage of hypercholesterolemic patients eligible for insurance coverage. However, in the US general population, the CDC has estimated that $36.7 \%$ of adults should be eligible for cholesterol lowering medications [3], with an LDLC range similar to our 734 patients referred to us for diagnosis and treatment of hypercholesterolemia.

\section{Conclusions}

Although the costs for PCSK9 inhibitors when given to an estimated 13 to 23 million patients would be extraordinary (\$185-342 billion), we speculate that if there was a $50 \%$ reduction in CVD, then there would be savings of $\$ 245$ billion, in the middle of the range of estimated PCSK9 inhibitor costs of \$185-342 billion. Whether the health care savings arising from the anticipated reduction of CVD on the PCSK9 inhibitors justify the broad population use of these agents remains to be determined.

\section{Abbreviations \\ CVD: cardiovascular disease; HeFH: heterozygous familial \\ hypercholesterolemia; LDLC: low density lipoprotein cholesterol.}

\section{Competing interests}

The authors declare that they have no competing interests.

\section{Authors' contributions}

Conception and Design: CJG, PS, NG, AK, MG. Acquisition of data, editing data: CJG, PS, NG, MP, AK, MG, PW. Analysis of data: CJG, PS, CJG, NG, PW. Drafting the manuscript CJG, PS, NG, MP, KL, VJ, AK, MG, PW. Given approval for final manuscript: CJG, PS, NG, MP, KL VJ, AK, MG, PW. Agree to be accountable: CJG, PS, NG, MP, KL VJ, AK, MG, PW. All authors read and approved the final manuscript. 


\section{Acknowledgement}

Supported in part by the Lipoprotein Research Fund of the Jewish Hospital of Cincinnati.

Received: 13 November 2015 Accepted: 9 March 2016

Published online: 12 March 2016

\section{References}

1. Robinson JG, Farnier M, Krempf M, Bergeron J, Luc G, Averna M, et al. Efficacy and safety of alirocumab in reducing lipids and cardiovascular events. N Engl J Med. 2015:372:1489-99.

2. Sabatine MS, Giugliano RP, Wiviott SD, Raal FJ, Blom DJ, Robinson J, et al. Efficacy and safety of evolocumab in reducing lipids and cardiovascular events. N Engl J Med. 2015;372:1500-9.

3. Mercado C, DeSimone AK, Odom E, Gillespie C, Ayala C, Loustalot F. Prevalence of cholesterol treatment eligibility and medication use among adults - united states, 2005-2012. MMWR Morb Mortal Wkly Rep. 2015;64:1305-11.

4. Grundy SM, Cleeman Jl, Merz CN, Brewer Jr HB, Clark LT, Hunninghake DB, et al. Implications of recent clinical trials for the national cholesterol education program adult treatment panel III guidelines. Circulation. 2004; 110:227-39.

5. Shrank WH, Barlow JF, Brennan TA. New therapies in the treatment of high cholesterol: an argument to return to goal-based lipid guidelines. JAMA. 2015:314:1443-4.

6. Risk of fatal coronary heart disease in familial hypercholesterolaemia. Scientific steering committee on behalf of the Simon Broome register group. BMJ. 1991;303:893-6.

7. Hsia SH, Desnoyers ML, Lee ML. Differences in cholesterol management among states in relation to health insurance and race/ethnicity across the United States. J Clin Lipidol. 2013;7:675-82.

8. Mann D, Reynolds K, Smith D, Muntner P. Trends in statin use and lowdensity lipoprotein cholesterol levels among US adults: impact of the 200 national cholesterol education program guidelines. Ann Pharmacother. 2008:42:1208-15

9. Waters DD, Brotons C, Chiang CW, Ferrieres J, Foody J, Jukema JW, et al. Lipid treatment assessment project 2: a multinational survey to evaluate the proportion of patients achieving low-density lipoprotein cholesterol goals. Circulation. 2009;120:28-34.

10. Glueck CJ, Budhani SB, Masineni SS, Abuchaibe C, Khan N, Wang P, et al. Vitamin D deficiency, myositis-myalgia, and reversible statin intolerance. Curr Med Res Opin. 2011;27:1683-90.

11. Khayznikov M, Hemachrandra K, Pandit R, Kumar A, Wang P, Glueck CJ. Statin intolerance because of myalgia, myositis, myopathy, or myonecrosis Can in most cases be safely resolved by vitamin D supplementation. N Am J Med Sci. 2015;7:86-93.

12. Robinson JG, Kastelein JJ. PCSK9 inhibitors and cardiovascular events. N Engl J Med. 2015;373:774.

13. Sabatine MS, Wasserman SM, Stein EA. PCSK9 Inhibitors and cardiovascular events. N Engl J Med. 2015;373:774-5

14. Stein EA, Raal FJ. Lipid-lowering drug therapy for CVD prevention: looking into the future. Curr Cardiol Rep. 2015;17:104.

15. Everett BM, Smith RJ, Hiatt WR. Reducing LDL with PCSK9 inhibitors-the clinical benefit of lipid drugs. N Engl J Med. 2015;373:1588-91.

16. Zhang XL, Zhu QQ, Zhu L, Chen JZ, Chen QH, Li GN, et al. Safety and efficacy of anti-PCSK9 antibodies: a meta-analysis of 25 randomized, controlled trials. BMC Med. 2015;13:123.

17. Label: PRALUENT- Alirocumab Injection, Solution." DailyMed. NIH: US National Library of Medicine, 16 Oct. 2015. Web. 10 Mar. 2016.

18. Elshazly MB, Martin SS, Blaha MJ, Joshi PH, Toth PP, McEvoy JW, et al. Non-high-density lipoprotein cholesterol, guideline targets, and population percentiles for secondary prevention in 1.3 million adults: the VLDL-2 study (very large database of lipids). J Am Coll Cardiol. 2013;62:1960-5.

19. Fryar CD, Chen TC, Li X. Prevalence of uncontrolled risk factors for cardiovascular disease: United States. NCHS Data Brief. 1999;2012:1-8.

20. Toth PP, Potter D, Ming EE. Prevalence of lipid abnormalities in the united states: the national health and nutrition examination survey 2003-2006. J Clin Lipidol. 2012;6:325-30.

21. Kuklina EV, Carroll MD, Shaw KM, Hirsch R. Trends in high LDL cholesterol, cholesterol-lowering medication use, and dietary saturated-fat intake: United States. NCHS Data Brief. 1976;2013:1-8.
22. Song X, Quek RG, Gandra SR, Cappell KA, Fowler R, Cong Z. Productivity loss and indirect costs associated with cardiovascular events and related clinical procedures. BMC Health Serv Res. 2015;15:245.

23. Heidenreich PA, Trogdon JG, Khavjou OA, Butler J, Dracup K, Ezekowitz MD, et al. Forecasting the future of cardiovascular disease in the United States: a policy statement from the American heart association. Circulation. 2011:123:933-44

24. Weintraub WS, Daniels SR, Burke LE, Franklin BA, Goff Jr DC, Hayman LL, et al. Value of primordial and primary prevention for cardiovascular disease: a policy statement from the American Heart Association. Circulation. 2011;124:967-90.

25. Milani RV, Lavie CJ. Impact of worksite wellness intervention on cardiac risk factors and one-year health care costs. Am J Cardiol. 2009;104:1389-92.

26. Arena R, Guazzi M, Briggs PD, Cahalin LP, Myers J, Kaminsky LA, et al. Promoting health and wellness in the workplace: a unique opportunity to establish primary and extended secondary cardiovascular risk reduction programs. Mayo Clin Proc. 2013:88:605-17.

27. Mozaffarian D, Benjamin EJ, Go AS, Arnett DK, Blaha MJ, Cushman M, et al. Heart disease and stroke statistics-2015 update: a report from the American Heart Association. Circulation. 2015;131:e29-e322.

28. Lipinski MJ, Benedetto U, Escarcega RO, Biondi-Zoccai G, Lhermusier T, Baker NC, et al. The impact of proprotein convertase subtilisin-kexin type 9 serine protease inhibitors on lipid levels and outcomes in patients with primary hypercholesterolaemia: a network meta-analysis. Eur Heart J. 2016:37:536-45.

29. Tuttle KR, Shuler LA, Packard DP, Milton JE, Daratha KB, Bibus DM, et al. Comparison of low-fat versus Mediterranean-style dietary intervention after first myocardial infarction (from The heart institute of spokane diet intervention and evaluation trial). Am J Cardiol. 2008;101:1523-30.

30. de Lorgeril M, Salen P, Martin JL, Monjaud I, Delaye J, Mamelle N. Mediterranean diet, traditional risk factors, and the rate of cardiovascular complications after myocardial infarction: final report of the Lyon diet heart study. Circulation. 1999;99:779-85.

31. Kelley GA, Kelley KS, Roberts S, Haskell W. Efficacy of aerobic exercise and a prudent diet for improving selected lipids and lipoproteins in adults: a meta-analysis of randomized controlled trials. BMC Med. 2011:9:74.

32. Grover SA, Ho V, Lavoie F, Coupal L, Zowall H, Pilote L. The importance of indirect costs in primary cardiovascular disease prevention: can we save lives and money with statins? Arch Intern Med. 2003;163:333-9.

33. Ohsfeldt RL, Gandhi SK, Smolen $\sqcup$, Jensen MM, Fox KM, Gold A, et al. Cost effectiveness of rosuvastatin in patients at risk of cardiovascular disease based on findings from the JUPITER trial. J Med Econ. 2010;13:428-37.

\section{Submit your next manuscript to BioMed Central and we will help you at every step:}

- We accept pre-submission inquiries

- Our selector tool helps you to find the most relevant journal

- We provide round the clock customer support

- Convenient online submission

- Thorough peer review

- Inclusion in PubMed and all major indexing services

- Maximum visibility for your research

Submit your manuscript at www.biomedcentral.com/submit
) Biomed Central 